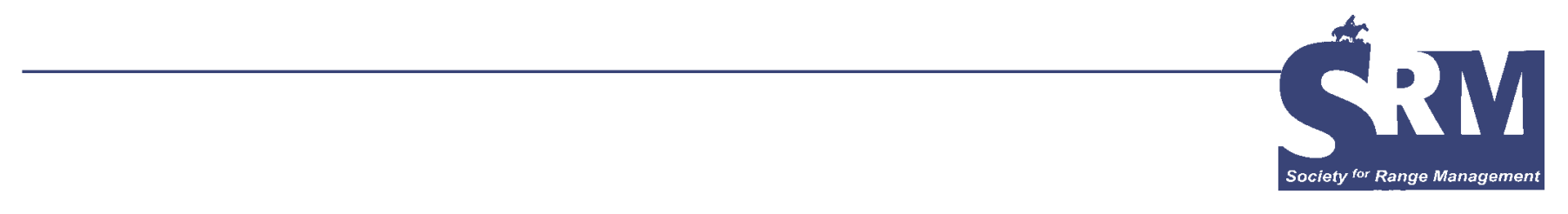

\title{
Climate Change and Ecosystems of the Southwestern United States
}

\section{By Steven R. Archer and Katharine I. Predick}

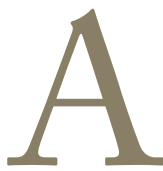

rid desert ecosystems of the western United States are particularly susceptible to climate change and climate variability. Plants and animals in this region live near their physiological limits for water and temperature stress. Slight changes in temperature or precipitation regimes or a change in the frequency and magnitude of extreme climatic events could therefore substantially alter the composition, distribution, and abundance of species, as well as the products and services that arid lands provide.

In the United States, arid lands are located in the subtropical hot deserts of the Southwest, comprised of the Mojave, Sonoran, and Chihuahuan deserts, and the temperate cold deserts of the Intermountain West. Annual precipitation is low $(<400 \mathrm{~mm})$, but the seasonality of precipitation differs substantially among hot deserts (Fig. 1). The Mojave Desert is dominated by winter precipitation; thus biological activity is greatest during the cool season. The Chihuahuan Desert is dominated by summer precipitation with biological activity during hotter conditions. The hottest of the three deserts, the Sonoran, is intermediate, receiving both winter and summer precipitation. Each of these deserts is characterized by low productivity and slow plant growth, both of which are primarily water-limited.

Vegetation communities are typically desert scrub, shrubsteppe, or desert grassland/savanna and are home to charismatic plants, including saguaro cacti, organ pipe cacti, and Joshua trees. The Chihuahuan Desert is the largest desert in North America, stretching from the southwestern United States deep into the Central Mexican Highlands. It has been classified by the World Wildlife Fund as a Global 200 Ecoregion, a science-based global ranking of the Earth's most biologically outstanding habitats. Arid lands currently provide a variety of products and services, including a large ranching industry, wildlife habitat, plant and animal diversity, regulation of water flow and quality, opportunities for outdoor recreation, and open spaces for expanding urban environments.

\section{Climate Projections for the Southwest}

Changes in temperature and precipitation over the past century now form a persistent pattern and show features consistent with the scientific understanding of climate change. The Climate Assessment for the Southwest (CLIMAS) program at the University of Arizona assesses the impacts of climate variability and longer-term climate change on human and natural systems in the Southwest. CLIMAS maintains an up-to-date record of climate forecasts and outlooks for the Southwest. There is broad consensus among climate models that the arid regions of the southwestern United States will become drier in the 21st century and that the transition to a more arid climate is already underway. The current prognosis for global climate change impacts on the Southwest include fewer frost days; warmer temperatures; greater water demand by plants, animals, and people; and an increased frequency of extreme weather events (heat waves, droughts, and floods). Furthermore, warmer nights and projected declines in snow pack, coupled with earlier spring snow melt, will reduce water supply, lengthen the dry season, create conditions for drought and insect outbreaks, and increase the frequency and intensity of wildfires. Temperatures currently considered unusually high will occur more frequently. These model-based projections align with observations made in the region over the past decade.

Precipitation predictions have a larger degree of uncertainty than predictions for temperature. These predictions 


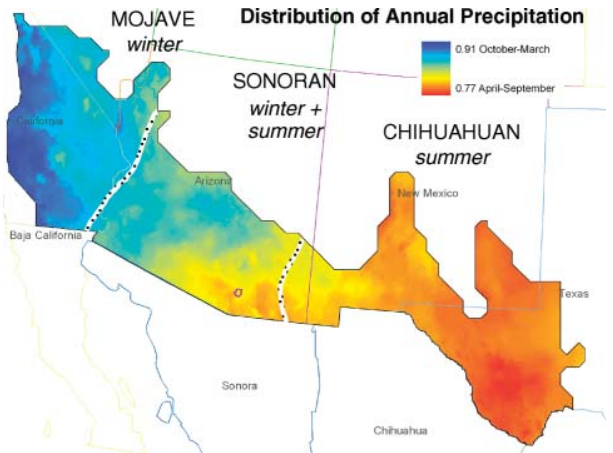

Figure 1. The seasonal distribution of precipitation ranges from summerdominated in the Chihuahuan Desert to winter-dominated in the Mojave Desert. Increases in temperature combined with changes in the amount and seasonality of precipitation will influence rangeland ecosystems. Image courtesy of Jennifer Davison and the University of Arizona Remote Sensing Center.

are based on continental-scale general circulation models that do not yet account for land use/land cover change effects on climate or important regional phenomena, such as those controlling monsoonal rainfall that are so important in much of the Southwest. Acknowledging those shortcomings, models project that precipitation will increase slightly in the eastern Chihuahuan Desert and decrease westward through the Sonoran and Mojave Deserts. These projections are consistent with trends observed in recent climate history. High-intensity storms will likely become more common. This will result in longer dry periods interrupted by highintensity rain storms and have the paradoxical effect of increasing both droughts and floods. Changes in temperature and precipitation will interact to directly impact vegetation and ecosystem processes in the Southwest. The widespread pinyon pine mortality in the Colorado Plateau in 2002-2003 could be a preview of things to come. The reductions in rainfall leading up to this die-off were comparable to those that occurred during the 1950s drought; yet pinyon pine die-off from the recent drought was far more extensive than that from the 1950s drought. This recent drought was devastating because consistently high temperatures occurred in conjunction with low precipitation.

\section{Impacts}

\section{The Geographic Boundaries of the Southwestern Deserts Will Likely Change}

With a decrease in the frequency of freezing temperatures, lengthening of the frost-free season, and increased minimum temperatures, the current boundaries of southwestern deserts will likely expand to the north and east. Biotic communities that characterize the Southwest are influenced by basin and range topography. Thus, within a given bioclimatic zone, communities transition from desert scrub and grassland to savanna, woodland, and forest along strong elevation gradients. Changes in climate will affect the nature of this zonation, with arid land community
Overview of Climate Change Impacts on Southwestern Ecosystems

- The response of arid lands to climate change will be strongly influenced by interactions with nonclimatic factors. Climate effects should be viewed in the context of these other factors, and simple generalizations should be viewed with caution.

- Plants and animals in arid lands live near their physiological limits. Slight changes in temperature and precipitation will substantially alter the composition, distribution, and abundance of species, impacts of land use, and the products and services that arid lands provide.

- Reductions in the frequency of freezing temperatures, lengthening of the frost-free season, and increased minimum temperatures will alter plant species ranges and shift the geographic and elevational boundaries of the Mojave, Sonoran, and Chihuahuan deserts. The extent of these changes will depend on changes in precipitation and fire regimes.

- Projected increases in the frequency and intensity of drought will cause major changes in vegetation cover. Higher temperatures and decreased soil moisture will likely reduce the stability of soil aggregates. Loss of vegetative cover and reduced soil aggregate stability, coupled with increases in precipitation intensity, will dramatically increase potential erosion rates. Transport of eroded sediment to streams, coupled with changes in the timing and magnitude of minimum and maximum flows, will affect water quality, riparian vegetation, and aquatic fauna. Wind erosion will have continental-scale impacts on downwind ecosystems, snow pack persistence, air quality, and human populations.

- Nonnative plant invasions will likely have a major impact on how arid land ecosystems respond to climate and climate change. Nonnative grasses generate large fuel loads that predispose arid lands to more frequent and intense fire than historically occurred. Such fires can radically transform diverse desert scrub, shrub-steppe, and desert grassland/savanna ecosystems into monocultures of nonnative grasses. This process is well underway in the cold desert region, and is in its early stages in hot deserts.

- Because of their profound impact on the fire regime and hydrology, nonnative plants in arid lands might trump direct climate impacts on native vegetation.

- Co-occurring changes in climate, atmospheric $\mathrm{CO}_{2}$, nitrogen deposition, and nonnative species invasions will lead to the development of novel wildland and managed ecosystems comprised of species occurring in both combinations and relative abundances that have not previously occurred. These novel ecosystems will present novel challenges for both conservation and management.

locations potentially moving up in elevation in response to warmer and drier conditions. Plants on "Sky Island" mountain tops might have no place to go as temperatures increase and snowpack and runoff decrease. 
Vegetation Composition, Diversity, and Growth Will All Likely Be Altered

Droughts in the 1950s and 2000s resulted in high mortality of perennial shrubs in the Sonoran and Mojave Deserts. The greater temperatures and higher rates of evapotranspiration predicted to co-occur with drought portend increased mortality for the dominant woody vegetation, and open the door for establishment of nonnative annual grasses adapted to "escape" drought conditions. Native annual plants are a major source of plant diversity in the North American deserts, but nonnative annuals have displaced native annuals during recent decades. Greater $\mathrm{CO}_{2}$ concentrations appear to benefit nonnative grasses and "weeds" more so than native species. Furthermore, atmospheric nitrogen deposition also appears to be tipping the balance toward nonnative annual plants. Nonnative perennial grasses utilize winter rain for growth more effectively than natives, and their ranges are likely constrained by low winter temperatures. Therefore, the abundance and range of nonnative grasses could increase in future climates. Saguaro density and growth decline with drought and reduced perennial shrub cover, so the range and abundance of this charismatic species likely will potentially decline. Conversely, limited available data suggest increases in atmospheric $\mathrm{CO}_{2}$ concentrations could promote Joshua Tree seedling survival, and could result in an increase of this native species' range. However, both of these species are likely to decline in abundance if subjected to fires resulting from establishment of nonnative grasses. Theory and shortterm, small-scale experiments suggest increased $\mathrm{CO}_{2}$ concentrations could favor $\mathrm{C}_{3}$ over $\mathrm{C}_{4}$ species. However, plant adaptations unrelated to carbon-photosynthetic pathway and interactions with other facets of change might constrain, or override, $\mathrm{C}_{3}-\mathrm{C}_{4}$ responses to atmospheric $\mathrm{CO}_{2}$ enrichment.

Net Primary Production (NPP) Is Likely to Decline NPP is likely to decline in response to reduced precipitation and higher temperatures. Interannual variability in NPP, already high in southwestern deserts, is likely to increase owing to increased climate variability, increased frequency of climatic extremes, and changes in plant functional group composition. Declines in NPP and nonnative annual plant invasions will reduce carbon storage in arid ecosystems, whereas higher temperatures will increase soil respiration and emissions of volatile organic carbon gases by plants. Thus, the potential for arid lands to sequester carbon and mitigate future climate change appears limited. Moreover, when remediation and restoration efforts are conducted in deserts, there can be substantial releases of $\mathrm{CO}_{2}$ from the fossil fuels used to pump irrigation water and conduct remediation and restoration practices.

Intensification of the Hydrologic Cycle Due to Atmospheric Warming Is Expected to Reduce Rainfall Frequency, But Increase the Intensity and/or Size of Individual Precipitation Events

A change in the size-class distribution of precipitation has important implications for instantaneous fluxes of $\mathrm{CO}_{2}$ from soils and the potential for ecosystems to sequester carbon. This is due to differences in the way soil microbial populations and plants respond to moisture entering the soil following rainfall events of different sizes. Larger rainfall events increase the wetting depth in the soil profile, and therefore should increase the number of periods within a year where plant activity and carbon storage can occur. Reducing the frequency of wet-dry cycles in soils will retard microbial activity and nutrient cycling, likely introducing a long-term nitrogen limitation to plant growth. For winter rainfall ecosystems, shifts in wet-dry cycles are known to cause reductions in NPP and soil carbon sequestration.

\section{Water Availability Likely Will Be Reduced in Arid Ecosystems}

Water inputs are expected to decline due to reduced precipitation. Water losses are also likely to increase due to elevated evapotranspiration rates at higher temperatures and greater run-off losses associated with increased frequencies of high intensity convectional storms. Urban expansion will also increase human demand for water and further reduce water availability for wildland ecosystems. Decreased water availability will impact riverine and riparian ecosystem function. Although these areas comprise a small fraction of arid lands, they provide critical habitat for arid land vertebrates and migratory birds. Reduced water inputs will cause riparian ecosystems to contract in size. Furthermore, lowered water availability will stress riparian plants and increase the ecosystem susceptibility to invasion by nonnative plants, such as salt cedar and Russian olive.

\section{Native Fish Diversity Will Likely Decline}

Fish in Southwestern streams and ponds currently live at the upper limits of aquatic vertebrate temperature tolerance. These streams are inhabited by unique assemblages of Southwestern native fish, many threatened and endangered. Climate change could affect persistence of native fishes by raising water temperatures to lethal levels and by providing more temperature-tolerant nonnative species with a competitive advantage. Native species that are particularly vulnerable include the Apache trout, Gila trout, Rio Grande cutthroat trout/chub/sucker, and Mohave tui chub.

\section{Soil Erosion Losses Are Expected to Increase}

Higher temperatures and decreased soil moisture will likely reduce the stability of soil aggregates, making the surface more erodible. Rainfall events are expected to decrease in occurrence, but increase in intensity. Therefore, erosive water forces will increase during high-intensity runoff events, and wind erosion will increase during intervening dry periods. Furthermore, decreases in vegetation cover, due to lower precipitation and disturbances such as fire or grazing, coupled with increases in wind speed and gustiness, will further increase wind erosion. Nitrogen is typically removed from the system during rain events or due to wind erosion, 
so increased wind and water erosion will result in a net nitrogen removal from the system. However, nitrogen deposition from increased urban land uses might offset some erosional nitrogen losses. Nutrient-rich soil removed from arid ecosystems will increase riverine sediment and nutrient loads, changing flow and water quality. Short- and longdistance transport of airborne dust can decrease air quality. Dust deposition on alpine snow pack would accelerate melting and potentially contribute to earlier seasonal drought conditions in lower stream reaches.

\section{Nonnative Species Are Likely to Increase in}

\section{Abundance}

Nonnative invasive species are a challenge for all ecosystems, but especially so in Southwestern arid lands, where nonnative invasive grasses encourage fire in desert ecosystems where fire was historically very rare. Climate change will interact with atmospheric $\mathrm{CO}_{2}$ enrichment and nitrogen deposition to potentially foster the establishment of nonnative species. Once established, nonnative species can accelerate the fire cycle in a self-reinforcing manner to invoke dramatic changes in Southwestern ecosystems. The slow growth and episodic nature of recruitment of many native arid land species constrains recovery from frequent fires that will accompany the establishment of nonnative annual and perennial grasses. The result is the potential for Southwestern desert communities to be quickly and radically transformed into near monocultures of nonnative species over large areas. This process is already in its early stages in hot deserts and mimics the well-known pattern observed for cheat grass (Bromus tectorum) in cold deserts (Chambers and Pellant, p. 29-33). Exurban development could facilitate nonnative species invasions by providing seed sources of nonnative species and fire ignition sources.

\section{Climate in a Land Use/Land Management Context}

The response of arid lands to climate change will be strongly influenced by interactions with nonclimatic factors, such as land use and nonnative species abundance. Climate change will influence both the types of future land use and the impacts of a specific land use. Climate change will occur concurrently with other environmental factors. Some of these factors might reinforce and accentuate climate effects (e.g., livestock grazing, nitrogen deposition); others might constrain, offset, or override climate effects (e.g., atmospheric $\mathrm{CO}_{2}$ enrichment, fire, nonnative species). Because many factors are affecting ecosystems simultaneously, it is difficult, and in many cases impossible, to separate the magnitude of each factor separately. The synergistic effects of these interacting factors often differ from the sum of the separate effects. Thus, climate effects should be viewed as the backdrop against which other factors act, and simple generalizations regarding climate effects should be viewed with caution.

\section{Invasive Plant Species}

Land use and climate markedly influence the probability, rate, and pattern of nonnative species invasions. Future changes in these drivers will interact to influence scenarios of ecosystem transformation. Nonnative species are advantaged by climate disturbances such as droughts and floods, both of which are likely to become more frequent and severe. Once established, nonnative grasses can generate large fuel loads that predispose arid lands to more frequent and intense fires than historically occurred with sparser native fuels. By virtue of their profound impact on the fire regime and hydrology, nonnative plants in arid lands will very likely surpass direct climate impacts on native vegetation where they gain dominance.

- Lehmann lovegrass (Eragrostis lehmanniana), a perennial African species, increased in abundance in the Upper Sonoran Desert after its introduction as a pasture forage in the first half of the 20th century, and is now making inroads in Chihuahuan Desert. Its success relative to native grasses appears related to its greater seedling drought tolerance and its ability to more effectively utilize winter moisture. Relatively wet periods associated with the Pacific Decadal Oscillation appear to have been more important than increases in $\mathrm{N}$-deposition or $\mathrm{CO}_{2}$ concentrations in the spread of this species.

- Buffelgrass (Pennisetum ciliare), like other neotropical exotics, is sensitive to low winter temperatures. The main invasion of buffelgrass into the Lower Sonoran Desert of southern Arizona occurred with warmer winters beginning in the 1980s, and its range will extend farther north and upslope as minimum temperatures continue to increase. This is complicated further by ongoing germplasm research seeking to breed more drought- and cold-resistant varieties for pasture plantings. For example, a cold-resistant "Frio" variety of buffelgrass was recently released and has been planted $40 \mathrm{~km}$ south of the Arizona border. The "Frio" variety has the potential to extend the invasive capability of buffelgrass northward in latitude and upward in elevation.

- Groundwater declines favor invasions of salt cedar (Tamarix ramosissima) and Russian olive (Elaeagnus angustifolia) in riparian areas and reduce the abundance of other riparian species and overall species richness.

Nonnative, invasive species often persist in low abundance for decades, then explode in abundance. We know very little about what triggers these dramatic changes, and we know very little about how ecosystem resistance to invasion by nonnatives will change in an altered climate. Other nonnative species currently "waiting the wings" in the southwestern deserts include red brome (Bromus rubens), Arabian schismus (Schismus arabicus), and redstem stork's bill (Erodium cicutarium).

Landscapes prone to desertification are already characterized by a high degree of interannual rainfall variability. Resource managers will be increasingly challenged if temperature, climate variability, and the frequency and intensity 
of extreme weather events and fires increase. Fuel management will become increasingly important in shrublands, woodlands, and areas invaded by nonnative perennial and annual grasses, particularly in areas with exurban development. Projected increases in temperature and a lengthening of the growing season could decrease the need for winter season supplementation of livestock. However, realization of this potential benefit will depend on precipitation. Many of the problems in arid/semiarid regions stem from the fact that livestock management systems are not agile enough to respond to fluctuations in precipitation. As a result, stocking rates are kept high for too long into drought periods, increasing the potential for degradation. Stocking rates will likely need to be more conservative if future degradation of Southwestern rangelands is to be averted. At the same time, physiological stresses associated with higher temperatures will very likely reduce livestock weight gains during summers, and this would be compounded by reductions in forage quality and quantity if precipitation decreased. Earlier springs and warmer winters will likely increase disease pressures in the form of pathogens and parasites. The economic viability of livestock operations thus could be challenged on numerous fronts.

Policies or coordination of regional management that promote stocking agility will be needed to prevent land degradation caused by grazing in a warmer, drier, more drought-prone world. In drylands, sustaining ecosystem processes in the face of climatic variability requires a sound foundation of monitoring and research, as well as a good working relationship between people and organizations with diverse goals and interests. Examples of community-based adaptive management, such as the Malpai Borderlands Group, illustrate the potential for coalitions of ranchers, agencies, scientists, and environmentalists to conserve ecosystem structure and function; in so doing, they protect a matrix of publicly and privately owned lands. Another model for this approach to conservation is the United Nations Educational, Scientific and Cultural Organization biosphere reserves program, wherein diverse assemblages of landscapes and cultures are protected within a matrix of different land ownerships, rather than a single governmentregulated entity. This collaboration between ranching, research, and conservation communities demonstrates that these groups, working together for mutual benefit, can reach scientific and conservation goals unobtainable by any one group on its own.

The current state of Southwestern arid lands reflects a legacy of historic land uses. Land use practices will arguably have a larger impact on arid land ecosystems in the next two to five decades than climate change. In the near-term, climate fluctuation and change will be important primarily as it influences the impact of land use and how ecosystems are impacted by, and respond to, land use. Grazing has traditionally been the most pervasive and extensive land use in arid lands. Although livestock grazing remains an important land use in arid lands, there has been a significant shift to exurban development and recreation, reflecting dramatic increases in human population density since 1950. Areas of Nevada, Arizona, and New Mexico are currently among the fastest growing in the United States. In addition to grazing, arid lands are now being exposed to new suites of environmental pressures such as air pollution, atmospheric nitrogen deposition, energy development, motorized off-road vehicles, feral pets, and invasion of nonnative plants.

\section{Monitoring Change}

Although the deserts of southwestern North America have been the sites of many important ecological studies, there have been relatively few long-term monitoring studies that provide the opportunity to observe changes in ecosystem structure and function in response to climate change per se. Coordinated measurements at sites spread across the Southwestern deserts would enhance our ability to detect change in ecosystem structure and function in relation to climate change. Several important data sets stand as benchmarks: the long-term vegetation and livestock management records at the Santa Rita and Jornada Experimental Ranges, the long-term perennial plant and winter annual plant studies at the United States Geological Survey Desert Laboratory at Tumamoc Hill in Tucson, the long-term data collected from large-scale ecosystem manipulations at Portal Arizona, and the new Mojave Desert Climate Change Program. Current observation systems are inadequate to separate the effects of changes in climate from the effects of other drivers (e.g., land use). There are few observing systems for monitoring wind and water erosion and for examining interactions among climatic and nonclimatic drivers. To identify climate effects would require a broad network, with many measured indicators, coupled with a network of controlled experimental manipulations. A coordinated national network that monitors ecosystem disturbance and recovery would greatly contribute to attributing disturbances to a particular cause, and identifying the consequences of those disturbances. However, no such network currently exists. Time-series satellite observations, coupled with ground-based measurements, can identify disturbance, changes in productivity, and changes in land use over time and over large, remote areas. However, ascribing changes in these metrics to climatic vs. nonclimatic factors is challenging. Lack of assured continuity for satellite observations could jeopardize these observations in the future.

\section{Future Outlook: Novel Ecosystems, Novel Challenges}

In novel ecosystems, species occur in combinations and relative abundances that have not occurred previously. Novel communities with a composition unlike any found today have occurred in the late-glacial past and will almost certainly 
develop in the anthropogenically altered world of the future. In climate simulations for the Intergovernmental Panel on Climate Change emission scenarios, novel climates arise by 2100 AD. These future novel climates (warmer than any present climates, with spatially variable shifts in precipitation) increase the likelihood of species reshuffling into novel communities and other ecological surprises. Within existing ecological communities, some species will persist, some species will depart, and new species will arrive, or evolve. Most ecological models are based upon modern observations, and so might fail to accurately predict ecological responses to future climates occurring in conjunction with elevated atmospheric $\mathrm{CO}_{2}$, nitrogen deposition, and nonnative species introductions. These novel ecosystems will present novel challenges and opportunities for conservation and management.

\section{Additional Reading}

Barnett, T. P., D. W. Pierce, H. G. Hidalgo, C. Bonfils, B. D. Santer, T. Das, G. Bala, A. W. Wood, T. Nozawa, A. A. Mirin, D. R. Cayan, and M. D. Dettinger. 2008. Human-induced changes in the hydrology of the western United States. Science 319:1080-1083.

ClimaS: Climate Assessment for the Southwest. 2007. Available at: http://www.climas.arizona.edu. Accessed 28 April 2008.
Institute for the Study of Planet Earth Publications. Available at: http://www.ispe.arizona.edu/resources/publications. html. Accessed 28 April 2008.

Lenart, M. [ED.]. 2007. Global warming in the Southwest: projections, observations and impacts. Climate Assessment for the Southwest. Tucson, AZ, USA: Institute for the Study of Planet Earth, University of Arizona. 88 p.

Malpai Borderlands Group. 2008. Available at: http://www. malpaiborderlandsgroup.org. Accessed 28 April 2008.

Sprigg, W. A., And T. Hinkley. 2000. Preparing for a changing climate: the potential consequences of climate variability and change. Report of the Southwest Regional Assessment Group, US Global Change Research Program. 66 p. Available at: http:// www.ispe.arizona.edu/research/swassess/report.html. Accessed 28 April 2008.

US Climate Change Science Program. 2007. The effects of climate change on agriculture, land resources, water resources, and biodiversity. Synthesis and Assessment Product 4.3. Available at: http://www.climatescience.gov/Library/sap/sap4-3/default.php. Accessed 28 April 2008.

A more extensive bibliography is available at http://www. rangelands.org/climatechange.shtml.

Authors are Professor, sarcher@Ag.arizona.edu (Archer) and Senior Research Associate (Predick), School of Natural Resources, University of Arizona, Tucson, AZ 85721-0043, USA. 